\title{
Status of Complications among Type 2 Diabetes Mellitus Patients Attending at Tertiary Health Care Centre, Karimnagar
}

\author{
G. Rajashekhar \\ Associate Professor, Department of General Medicine, Chalamada Ananda Rao Institute of Medical Sciences, \\ Karim Nagar, Telangana State
}

\begin{abstract}
Background: Type 2 diabetes mellitus is a chronic manageable illness and it resulted due to absence or insufficient insulin production. As the disease is in chronic condition, patients tend to neglect their health due to cost of the medicine, secondly adherence to medication and taking care about other parts like foot and peripheries. Finally it affects directly or indirectly affect the quality of life due to development of long term complications. Aim of the study is to find the demographic factors and risk factors associated with long term complications of the Diabetes. Methodology: A cross sectional study was conducted among the outpatient attendees at Chalamada Ananda Rao Institute of Medical sciences during the period from October 2020 to March 2021 among the 233 patients. Data entered in Micro soft Excel and appropriate statistical tests like simple proportions and chi square test were applied. Results: In the present study, about 51\% were in the age group of 51-60 years and males were $48 \%$. In the current study, smoking and alcohol consumption were significantly associated with long term complications of neuropathy, retinopathy and nephropathy $(\mathrm{P}<0.001)$. Conclusions: Based on the study results, risk factors like smoking and alcohol consumption to be reduced as far possible. In addition to our regular care special counselling sessions to be planned with trained health educators. Need lifestyle modifications adaptation among diabetic and even non diabetic people we can suggest as a primordial prevention.
\end{abstract}

Key words: Gender, Type 2 diabetes, Diabetic neuropathy, Diabetic retinopathy, Diabetic nephropathy.

\section{Introduction}

Diabetes Mellitus incidence and prevalence was gradually increasing for the last 3-4 decades

\section{Corresponding author:}

Dr. G. Rajashekhar, Associate Professor, Department of General Medicine, Chalamada Ananda Rao Institute of Medical Sciences, Karim Nagar, Telangana State. Mobile number: +91 8465801973 , Email: aryang05@gmail.com due to chronic nature of the disease, changes in food lifestyle including fast food intake, mechanical life, less physical activity, high fat intake, refined carbohydrates intake, family history, stress and also non modifiable factors like age, gender and ethnicity ${ }^{1}$.

Prolonged hyperglycaemia tend to develop certain macro vascular and micro vascular complications. The common macro vascular complications like coronary heart disease, peripheral heart disease and stroke. As the duration of type 2 diabetes is increasing, there is a tend to develop certain acute complications like 
hypoglycaemia and hyperglycaemia and long term complications like including peripheral neuropathy, diabetic retinopathy, diabetic nephropathy and micro angiopathy etc. Of all the micro vascular vascular complications, diabetetic neuropathy is most common debilitating complication. These complications may cripple the physical and mental activities of the person. Once diabetic neuropathy is developed, there is a tend to inability to perceive certain sensations like touch, pain, cold, heat at extremities due to consequence damage to the nerves. As a result of this complication, diabetic patients can develop some sores or ulcers on the peripheral extremities, over a period of time patients chances of losing their limbs, once gangrene is developed ${ }^{2,3}$.

In view of the above situations and circumstances, the present study was planned and conducted at Teriary care hospital, Karimnagar to identify the complications and planned to educate the people during our regular visits and in addition to our regular practice at this institute.

\section{Objectives:}

1. To find the demographic and social factors in the study population.

2. To find the some risk factors association with long term complications of the diabetes, in relation to gender, smoking, physical activity, alcohol consumption in the study population.

\section{Methodology}

A cross sectional study was conducted at Internal Medicine outpatient Department of tertiary care hospital of Chalamada Ananda Rao Institute of Medical Sciences during the period from October 2020 to march 2021. A total of 192 patients participated in the study and response rate was $82 \%$ in the study. Some of the common definitions taken for the consideration of Diabetic neuropathy was considered as patients were presenting with numbness, paraesthsia and tingling numbness. Fundus examination was considered to detect the Diabetic retinopathy and its stages, lastly incipient nephropathy was considered as by micral test (Microalbuminuria 30-300mg/24 hrs) and overt diabetic nephropathy was based on serum creatinine, blood urea and macroalbuminuria ${ }^{4,5}$.

Target population: All the diabetic patients visited to outpatient department of the hospital.

Study Design: A cross sectional study was conducted at General Medicine outpatient department of Chalamada Ananda Rao Institute of Medical Sciences.

Study period: From the period from October 2020 to March 2021 among type 2 diabetes patients.

Sample Size: Based on the previous studies prevalence of diabetic neuropathy among the diabetes people taken as $32.2 \%$, absolute precision is $6 \%$ and at $95 \%$ confidence interval, sample size was 233.

Sampling method: As the study duration is 6 months, hence all the diabetics fitted to my study design and interviewed with questionnaire and collected information from the individual and also from laboratory of the hospital for Fasting blood sugar level and $\mathrm{HbA} 1 \mathrm{c}$ value.

\section{Exclusion Criteria:}

Type 1 Diabetic patients by age less than 40 years.

Newly detected Diabetes people and Diabetes duration less than 5 years were excluded in the study.

Gestational Diabetes or Diabetes among the pregnancy.

Inclusion criteria: All the old Diabetic patients visited, with duration of the Diabetes more than 5 years attended at Outpatient department and their age more than 40 years were included. 
Ethical considerations: After approval of the Institutional ethical committee certificate, present study was conducted. Before collection of the information from the participant, informed consent was taken and confidentiality of the personal information was maintained and privacy of the participant was protected.

Statistical Analysis: Data was entered in Microsoft office Excel and necessary statistical tests like simple proportions, for categorical analysis chi square test and fisher exact tests were applied. Confidentiality of the patients was maintained at all the levels.

Results: The present study was conducted among the 233 study participants. Of which 192 participants completed the questionnaire and remaining people considered as non cooperative people, some refused and some patients lab parametres were not available and non co-operative in other examinations. Hence in our study, the response rate was $82.4 \%$ (192/233).

Table 1: Socio demographic variables among the study population:

\begin{tabular}{|c|c|c|}
\hline Variables & Number of the patients & Percentage \\
\hline \multicolumn{3}{|c|}{ Age } \\
\hline $40-50 \mathrm{yrs}$ & 80 & 41.6 \\
\hline $51-60 \mathrm{yrs}$ & 98 & 51 \\
\hline$>60 \mathrm{yrs}$ & 14 & 7.4 \\
\hline Total & 192 & 100 \\
\hline \multicolumn{3}{|c|}{ Gender } \\
\hline Male & 92 & 47.9 \\
\hline Female & 100 & 52.1 \\
\hline Total & 192 & 100 \\
\hline \multicolumn{3}{|c|}{ Occupation } \\
\hline Employed & 83 & 43.2 \\
\hline Unemployed & 109 & 56.8 \\
\hline Total & 192 & 100 \\
\hline \multicolumn{3}{|c|}{ Family income } \\
\hline$<6000 /$ month & 116 & 60.4 \\
\hline$>6000 /$ month & 76 & 39.6 \\
\hline Total & 192 & 100 \\
\hline
\end{tabular}


Table 1 stated that in the study population, accounts 51\%, 60 years and above patients were about majority of the patients between 51-60 years and it 74\%. 52.1\% were females in the current study. About $60.4 \%$ participants income was $<6000 /$ month.

Table: 2- Frequency of lifestyle factors in the study population

\begin{tabular}{|c|c|c|}
\hline Life style factors & Number & Percentage \\
\hline Smokers & 64 & $33.4 \%$ \\
\hline Non-smokers & 128 & $66.6 \%$ \\
\hline Physical activity present & 88 & $45.9 \%$ \\
\hline Physical activity absent & 104 & $54.1 \%$ \\
\hline Alcohol consumption present & 35 & $18.3 \%$ \\
\hline No Alcohol consumption & 157 & $81.7 \%$ \\
\hline Glycaemic control $<7 \mathrm{gm} \%$ & 76 & $39.6 \%$ \\
\hline Glycaemic control $>7$ gm $\%$ & 116 & $60.4 \%$ \\
\hline
\end{tabular}

Table 2 revealed that in the study diabetes population, about $33.4 \%$ were smokers, physical activity practising people were $45.9 \%$ and alcohol consumption people were $18.3 \%$.

Table: 3- Complications status among the study population:

\begin{tabular}{|c|c|c|}
\hline Complications & Number & Percentage \\
\hline Diabetic retinopathy & 53 & $27.6 \%$ \\
\hline Diabetic neuropathy & 60 & $31.2 \%$ \\
\hline Diabetic nephropathy & 50 & $26 \%$ \\
\hline
\end{tabular}

Table 3 highlighted that in the diabetes patients, about 31.2\% were having diabetic neuropathy, diabetic retinopathy about $27.6 \%$ and diabetic nephropathy people were about $26 \%$. 
Table: 4- Gender in relation to some long term Diabetes Complications in study group.

\begin{tabular}{|c|c|c|c|c|c|c|}
\hline Gender & $\begin{array}{c}\text { Diabetic } \\
\text { neuropathy } \\
\text { present }\end{array}$ & $\begin{array}{c}\text { Diabetic } \\
\text { neuropathy } \\
\text { absent } \\
\text { retinopathy } \\
\text { present }\end{array}$ & $\begin{array}{c}\text { Diabetic } \\
\text { retinopathy } \\
\text { absent }\end{array}$ & $\begin{array}{c}\text { Diabetic } \\
\text { nephropathy } \\
\text { present }\end{array}$ & $\begin{array}{c}\text { Diabetic } \\
\text { nephropathy } \\
\text { absent }\end{array}$ \\
\hline Male & $34(36.9 \%)$ & $58(63.1 \%)$ & $30(32.6 \%)$ & $62(67.4 \%)$ & $28(30.4 \%)$ & $64(69.6 \%)$ \\
\hline Female & $26(26 \%)$ & $74(74 \%)$ & $23(23 \%)$ & $77(77 \%)$ & $22(22 \%)$ & $78(78 \% 0$ \\
\hline Total & $60(31.2 \%)$ & $132(68.8 \%)$ & $53(27.6 \%)$ & $139(72.4 \%)$ & $50(26 \%)$ & $142(74 \%)$ \\
\hline
\end{tabular}

Table 4 depicted that about $36.9 \%$ of males were having diabetic neuropathy complication, $32.6 \%$ males were having retinopathy and lastly $30.4 \%$ males were having diabetic nephropathy complication. There was no significant association was found between gender and long term complications of Diabetes $(\mathrm{P}>0.05)$.

Table: 5 - Some risk factors according to long term diabetes complications status in study population.

\begin{tabular}{|c|c|c|c|c|c|c|}
\hline Risk factors & $\begin{array}{c}\text { Diabetic } \\
\text { neuropathy } \\
\text { Yes }\end{array}$ & $\begin{array}{l}\text { No Diabetic } \\
\text { neuropathy }\end{array}$ & $\begin{array}{c}\text { Diabetic } \\
\text { retinopathy }\end{array}$ & $\begin{array}{l}\text { No Diabetic } \\
\text { retinopathy }\end{array}$ & $\begin{array}{r}\text { Diabetic } \\
\text { nephropat }\end{array}$ & $\begin{array}{l}\text { No Diabetic } \\
\text { nephropathy }\end{array}$ \\
\hline Smokers & $40(62.5 \%)$ & $24(37.5 \%)$ & $37(57.8 \%)$ & $27(42.2 \%)$ & $41(64 \%)$ & $23(36 \%)$ \\
\hline Non smokers & $20(15.6 \%)$ & $108(84.4 \%)$ & $16(12.5 \%)$ & $112(87.5 \%)$ & $09(7 \%)$ & $119(93 \%)$ \\
\hline & \multicolumn{2}{|c|}{ X 2 - 43.63, P - 0.0001.} & \multicolumn{2}{|c|}{ X $2-43.83, P-0.0001$} & \multicolumn{2}{|c|}{ X $2-72.05, P-0.00001$} \\
\hline $\begin{array}{c}\text { Phy.activity } \\
\text { Present }\end{array}$ & $25(28.4 \%)$ & $63(71.6 \%)$ & $21(23.8 \%)$ & $67(76.2 \%)$ & $20(22.7 \%)$ & $68(77.3 \%)$ \\
\hline $\begin{array}{c}\text { No Physical } \\
\text { activity }\end{array}$ & $35(33.6 \%)$ & $69(66.4 \%)$ & $32(30.7 \%)$ & $72(69.3 \%)$ & $30(28.8 \%)$ & $74(71.2 \%)$ \\
\hline
\end{tabular}




\section{Cont... Table: 5 - Some risk factors according to long term diabetes complications status in study population.}

\begin{tabular}{|c|c|c|c|c|c|c|}
\hline & \multicolumn{2}{|c|}{ X 2- 0.61, P- 0.43 } & \multicolumn{2}{c|}{ X 2- 1.13, P - 0.28 } & \multicolumn{2}{c|}{ X 2 - 0.92, P - 0.33 } \\
\hline $\begin{array}{c}\text { Alcohol } \\
\text { consumption } \\
\text { present }\end{array}$ & $25(71.4 \%)$ & $10(28.6 \%)$ & $21(60 \%)$ & $14(40 \%)$ & $24(68.5 \%)$ & $11(31.5 \%)$ \\
\hline $\begin{array}{c}\text { Alcohol } \\
\text { consumption } \\
\text { absent }\end{array}$ & $35(22.2 \%)$ & $122(77.8 \%)$ & $32(20.3 \%)$ & $125(79.7 \%)$ & $26(16.5 \%)$ & $131(83.5 \%)$ \\
\hline & X 2-32.16, P- 0.0001 & X 2- 22.47, P - 0.001 & X 2- 40.19, P - 0.00001 \\
\hline
\end{tabular}

Table 5 revealed that about $62.5 \%$ were having diabetic neuropathy complication, similarly diabetic retinopathy and diabetic nephropathy complications among the smokers were $57.8 \%$ and $64 \%$ respectively. Among the physical activity practising people diabetic neuropathy was $28.4 \%$ and where as in physical activity not practising people about $33.6 \%$. Similarly alcohol consuming study group, diabetic neuropathy complication was $71.4 \%$. Diabetic retinopathy was $60 \%$ and diabetic nephropathy was found $68.5 \%$ among the alcohol consuming study population.

\section{Discussion}

There were many studies conducted on prevalence of long term complications among the type 2 Diabetes mellitus patients and seen association with demographic characteristics with long term complications. Very studies conducted to see the associations between life style factors with long term complications of diabetes mellitus in the world as well as in India. To the best of my knowledge, our study was the first study in our institute, in our district.

In our present study the response rate was $82.4 \%$ (192/233). Similar finding of response rate was observed with study conducted in Manipal university teaching tertiary care hospital, Mangalore ${ }^{1}$. In the present study, elderly population aged more than 60 years people were $7.4 \%$ and almost similar finding observed with as per the Government of India existing National Statistics revealed that $7.5 \%$ of elderly population were present in India ${ }^{8}$.

In the current study, about $33.4 \%$ were smokers and $18.3 \%$ were alcohol consumed people were observed. About 31.2\% were having diabetic neuropathy complication, which was quite common complication observed in our routine practice in our settings. There were many studies conducted on diabetic neuropathy complication prevalence throughout the globe and prevalence wide ranging from $13-75 \%$. This much variation could be based on sample size, clinical settings, wide economic variations and geographical variations and locations 9-11. Almost similar prevalence $(32.2 \%)$ of diabetic neuropathy was observed in a study conducted in South India, ${ }^{1}$ a study conducted in USA showed as $21.5 \%$ diabetic neuropathy ${ }^{10}$, another study in Turkey revealed that the diabetic peripheral neuropathy was 
$60 \%{ }^{12}$ and study conducted in Iran in the year 2006 showed diabetic neuropathy prevalence was $75 \%{ }^{11}$.

In our study, in relation to association between smoking and diabetic neuropathy was statistically significant (P-0.001). A study conducted in Saudi Arabia stated that smoking was significantly associated with long term complications neuropathy and retinopathy respectively ( $>2$ times relative risk and more than 2 times odd's ratio) and even study done in India also stated that the same finding of smoking was significantly associated with the complications of neuropathy and retinopathy ${ }^{1,5,10}$. Another studies conducted in United States and United Kingdom and stated that smoking increased 3-7 times more morbidity among the IDDM and NIDDM individuals ${ }^{6}$.

Diabetic retinopathy was diagnosed by detailed fundus examination and in our study reported as $27.6 \%$. Similar prevalence of diabetic retinopathy was observed in study conducted in the United Kingdom as $25 \%$ to $27 \%{ }^{14}$. Little more prevalence of Diabetic retinopathy was observed in studies conducted in European countries like Sweden, Denmark and Italy ranging from $30 \%$ to $40 \%{ }^{15,16}$. Relatively little low prevalence of diabetic retinopathy was noticed based on studies conducted in Asian countries 17,18. World largest population country in the world as per current population estimates, China also noticed different spectrum of diabetic retinopathy prevalence ranging from $28 \%$ to $43 \%{ }^{19,20}$.

In the present study, diabetic nephropathy was diagnosed based on micral test and reported as $26 \%$. Almost very similar finding was observed with study conducted in South India by Chennai Urban epidemiology unit and also stated that smoking was significantly associated with Diabetic nephropathy ${ }^{21}$. Similar observation of diabetic nephropathy complication of $26 \%$ prevalence was noticed among the population based study among the type 2 diabetic patients in Southwest Finland ${ }^{22}$.
One of the limitation was due to COVID 19 situation, due to lock downs, I faced little difficulty in collect the data from the patients and even their follow up visits also got delayed. Another limitation in the study was other long term complications like Diabetic gastropathy and erectile dysfunction and other micro vascular complications like stroke and coronary heart disease were excluded in the present study due to time constraints. As our study was cross sectional study, small sample size, generalization of the findings to the whole population was not advisable and similar studies are required to substantiate our study findings. But, this study will give some insight about long term complications among the diabetic patients and will be utilized for management plans and education to the patients visiting to our clinical settings.

\section{Conclusions}

Based on the study results, almost close to one third of the patients were diabetic neuropathy complication patients and little less prevalence of diabetic retinopathy $(27.6 \%)$ and diabetic nephropathy $(26 \%)$ were observed and also all the three complications significantly associated with lifestyle factors like smoking and alcohol consumption.

Funding: Not received any external funding for this study.

\section{Conflict of Interest: None}

Institutional ethical Committee approval was taken.

Acknowledgments: Our sincere thanks to all our study participants, interns posted in our department, who helped for the successful and in time completion of the study.

\section{References}

1. D'Souza M, Kulkarni V, Unnikrishnan Bhaskaran HA, Naimish H, Prakash A, Tabreez S, Dahiya 
B, Thapar R, Mithra P, Kumar N, Ramesh Holla DB. Diabetic peripheral neuropathy and its determinants among patients attending a tertiary health care centre in Mangalore, India. Journal of public health research. $2015 \mathrm{Jul} 16 ; 4(2)$.

2. Harris MI, Klein R, Welborn TA, Knuiman MW. Onset of NIDDM occurs at least 4-7 yr before clinical diagnosis. Diabetes care. 1992 Jul $1 ; 15(7): 815-9$.

3. Shobana R, Augustine C, Ramachandran A, Vijay V. Improving psychosocial care: The Indian experience. Diabetes Voice. 2005;50(1):19-21.2.

4. Agrawal R, Ola V, Bishnoi P, Gothwal S, Sirohi P, Agrawal R. Prevalence of micro and macrovascular complications and their risk factors in type-2 diabetes mellitus. JAPI. 2014 Jun;62:505.

5. Ahmad MS, Alslamah T, Alannaz SM, Shaik RA, Ahmad RK, Yusuf M, Khan M, Ghimire A. Prevalence of micro and macro vascular complications and their risk factors in type 2 diabetes in Saudi Arabian population: an analysis from SHIS. European Review for Medical and Pharmacological Sciences. 2021 Jun 1;25(12):4308-16. (KSA Smoking)

6. Gay EC, Cai Y, Gale SM, Baron A, Cruickshanks KJ, Kostraba JN, Hamman RF. Smokers with IDDM experience excess morbidity. The Colorado IDDM Registry. Diabetes Care 1992; 15: 947-952. (Smoking)

7. Morrish NJ, Stevens LK, Fuller JH, Jarrett RJ, Keen H. Risk factors for macrovascular disease in diabetes mellitus: the London follow-up to the WHO Multinational Study of Vascular Disease in Diabetics. Diabetologia 1991; 34: 590-594. (Smoking)

8. The Registrar General \& Census Commissioner, India. Census Data Online. 2001. Available from: http://www.censusindia.gov.in/2011- common/ censusdataonline.html

9. Mørkrid K, Ali L, Hussain A. Risk factors and prevalence of diabetic peripheral neuropathy: A study of type 2 diabetic outpatients in Bangladesh. Int J Diabetes Dev Ctries 2010;30:11-7.

10. Koopman RJ, Mainous AG, Liszka HA, et al. Evidence of nephropathy and peripheral neuropathy in US adults with undiagnosed diabetes. Ann Fam Med 2006;4:427-32.

11. Janghorbani M, Rezvanian H, Kachooei A, et al. Peripheral neuropathy in type 2 diabetes mellitus in Isfahan, Iran: prevalence and risk factors. Acta Neurol Scand 2006;114:84-91.

12. Rota E, Quadri R, Fanti E, et al. Electrophysiological findings of peripheral neuropathy in newly diagnosed type II diabetes mellitus. J Peripher Nerv Syst 2005; 10:348-53.

13. Ting DS, Cheung GC, Wong TY. Diabetic retinopathy: global prevalence, major risk factors, screening practices and public health challenges: a review. Clinical \& experimental ophthalmology. 2016 May;44(4):260-77.

14. Giuffre G, Lodato G, Dardanoni G. Prevalence and risk factors of diabetic retinopathy in adult and elderly subjects: The Casteldaccia Eye Study. Graefe's archive for clinical and experimental ophthalmology $=$ Albrecht von Graefes Archiv fur klinische und experimentelle. Ophthalmologie 2004; 242: 535-40.

15. Knudsen LL, Lervang HH, LundbyeChristensen S, Gorst-Rasmussen A. The North Jutland County Diabetic Retinopathy Study: population characteristics. $\mathrm{Br} \quad J$ Ophthalmol 2006; 90: 1404- 9. (25)

16. Varma R, Ying-Lai M, Klein R, Azen SP. Los Angeles Latino Eye Study G. Prevalence and risk indicators of visual impairment and blindness in Latinos: the Los Angeles Latino Eye Study. Ophthalmology 2004; 111: 1132-40. (27). 
17. 36He S, Guo Y, Li Z. Epidemiologic study of diabetic retinopathy in Capital Steel Company]. [Zhonghua yan ke za zhi. Chinese journal of ophthalmology 1997; 33: 381-3.

18. Raman R, Rani PK, Reddi Rachepalle S, et al. Prevalence of diabetic retinopathy in India: Sankara Nethralaya Diabetic Retinopathy Epidemiology and Molecular Genetics Study report 2. Ophthalmology 2009; 116: 311-8.

19. Wang FH, Liang YB, Zhang F, et al. Prevalence of diabetic retinopathy in rural China: the Handan Eye Study. Ophthalmology 2009; 116: 461- 7.

20. Xie XW, Xu L, Wang YX, Jonas JB. Prevalence and associated factors of diabetic retinopathy. The Beijing Eye Study 2006. Graefe's archive for clinical and experimental ophthalmology. Albrecht von Graefes Archiv fur klinische und experimentelle Ophthalmologie 2008; 246: 1519- 26.

21. Unnikrishnan R, Rema M, Pradeepa R, Deepa M, Shanthirani CS, Deepa R, Mohan V. Prevalence and risk factors of diabetic nephropathy in an urban South Indian population: the Chennai Urban Rural Epidemiology Study (CURES 45). Diabetes care. 2007 Aug 1;30(8):2019-24.

22. Wirta OR, Pasternack AI, Oksa HH, Mustonen JT, Koivula TA, Helin HJ, Lähde YK. Occurrence of late specific complications in type II (non-insulin-dependent) diabetes mellitus. Journal of diabetes and its complications. 1995 Jul 1;9(3):177-85. 